\title{
Systemic administration of strontium ranelate to enhance the osseointegration of implants: systematic review of animal studies
}

\author{
Cassio Rocha Scardueli ${ }^{1,2^{*}}$, Carolina Bizelli-Silveira ${ }^{1}$, Rosemary Adriana C. Marcantonio ${ }^{2}$, Elcio Marcantonio Jr ${ }^{2}$, \\ Andreas Stavropoulos ${ }^{3}$ and Rubens Spin-Neto ${ }^{1}$
}

\begin{abstract}
The literature states that Strontium (Sr) is able to simultaneously stimulate bone formation and suppress bone resorption. Recent animal studies suggest that the systemic administration of $\mathrm{Sr}$, in the form of strontium ranelate (SRAN), would enhance the osseointegration of implants. The purpose of the present study was to undertake a systematic review on animal studies evaluating the systemic administration of Sr to enhance the osseointegration of titanium implants and the remodeling of bone grafts. The MEDLINE (PubMed) and Scopus bibliographic databases were searched from 1950 to October 2017 for reports on the use of systemic and non-radioactive Sr to enhance the osseointegration of titanium implants and the remodeling of bone grafts in animals. The search strategy was restricted to English language publications using the combined terms: "strontium" and "implant or graft or biomaterial or bone substitute". Five studies were included, all related to the systemic administration of Sr in the form SRAN, and its effects on osseointegration of titanium implants. No studies on the use of SRAN-based therapy to enhance the remodeling of bone grafts were found. The studies differed notably with respect to the study population (healthy female rats, healthy male rats, and female rats with induced osteoporosis) and SRAN dose (ranging from 500 to $1000 \mathrm{mg} / \mathrm{kg} /$ day). Results were diverse, but a tendency suggesting positive influence of systemic SRAN administration on the osseointegration of titanium implants was observed. No major side-effects due to strontium administration were reported. Systemic Sr administration, in the form of SRAN, seems to enhance peri-implant bone quality and implant osseointegration in animals, however, at a moderate extent. Further studies, evaluating both the effects of this drug on implant osseointegration and the risk/benefit of its use, are needed to provide a rationale of this therapeutic approach.
\end{abstract}

Keywords: Strontium, Systemic use, Osseointegration, Bone remodeling

\section{Introduction}

Following the trauma induced to the bone tissue during dental implant installation, wound healing involves the fine-tuned coupling of bone resorption and formation $[1,2]$, which finally leads to the direct bone-to-implant contact, i.e., implant osseointegration [3]. The same

\footnotetext{
* Correspondence: cassiorochas@hotmail.com

${ }^{1}$ Department of Dentistry and Oral Health, Aarhus University, Aarhus, Denmark

${ }^{2}$ Department of Periodontology, São Paulo State University (Unesp), School of Dentistry, Araraquara, São Paulo, Brazil

Full list of author information is available at the end of the article
}

biological mechanisms are involved in the wound healing (i.e., remodeling) of a bone defect filled with bone graft and/or bone substitute material [4]. In order to enhance wound healing and thereby achieve an optimized osseointegration and/or bone defect closure, systemic-, and local administration of drugs, including growth and differentiation factors, and/or implant and graft drugbased surface modifications have been employed with variable success $[5,6]$. In the past years, the literature regarding the local interventions (mostly based on the modification of implant surfaces to improve the osseointegration process) became highly developed [6]. On the 
other hand, the additional effect of systemic therapies supplementing such local modification factors, although acknowledged, was not developed in a similar manner [5].

Examples of systemic administration of anabolic and anticatabolic substances include estrogen [7], parathyroid hormone [8], and bisphosphonates $[9,10]$. In particular, systemic administration of bisphosphonates, which are widely used for cancer and osteoporosis treatment, is based on the rationale that suppression of bone resorption-achieved by this type of drugs-results in denser peri-implant bone and thereby in larger amounts of bone-to-implant contact [11]. Indeed, a recent review of animal studies indicated that systemic administration of bisphosphonates enhances implant osseointegration, especially in animals with induced osteoporotic conditions [12]. Nevertheless, the increasing number of reports in recent years of bisphosphonate-related osteonecrosis of the jaws has raised alarm regarding the side-effects of bisphosphonate treatment [13] and has led to the search of alternatives to this group of drugs.

Another type of drug recently developed for osteoporosis treatment is strontium ( $\mathrm{Sr}$ ) ranelate (SRAN) [14-16]. This drug is a salt consisting of two atoms of stable strontium $\left(\mathrm{Sr}^{2+}\right)$ and an organic acid (Ranelic acid), and it is usually administrated orally $[17,18]$. Sr ions possess a high affinity to hydroxyapatite (HA) [19], and in contrast to bisphosphonates that decrease bone resorption, $\mathrm{Sr}$ exerts a dual action, i.e., it is able to simultaneously stimulate bone formation and suppress bone resorption $[17,20,21]$. This has been demonstrated in both animal(by means of bone mineral content analysis [22], dualenergy X-ray absorptiometry [23], and histomorphometric assessment [24]), and clinical studies (by means of microtomography and histomorphometric assessment) [25]. Further, relatively recent reports from animal studies suggest that the systemic administration of $\mathrm{Sr}$ would enhance the osseointegration of implants.

Thus, the aim of this review was to undertake a systematic review of the literature on the available evidence-deriving from animal studies-on the systemic administration of non-radioactive $\mathrm{Sr}$ to enhance the osseointegration of titanium implants and/or the bone regeneration (i.e., remodeling) in association with bone grafting techniques.

\section{Material and methods}

This review was executed in accordance with PRISMA (Preferred Reporting Items for Systematic Reviews and Meta-Analyses) [26], and the Cochrane Handbook for Systematic Reviews of Interventions [27].

\section{Criteria for considering studies for this review}

Animal studies in which the methodology/results included parameters regarding the use of systemic administration of non-radioactive $\mathrm{Sr}$ to enhance the osseointegration of implants and/or the remodeling of bone (and bone substitute materials) grafts qualified for inclusion. Retrieval of information focused on (1) the used posology (dose and timing), (2) the type of treatment, (3) the assessed outcome, and (4) the side effects of the treatment. Studies which failed reporting one or more of these four topics still qualified for inclusion, but the missing information was acknowledged as nondeclared.

\section{Search strategy for identification of studies Electronic search}

The MEDLINE (Medical Literature Analysis and Retrieval System Online, via PubMed) and Scopus databases were searched until October 2017 for studies evaluating the use of systemic non-radioactive $\mathrm{Sr}$ to enhance to enhance the osseointegration of titanium implants and the remodeling of bone grafts. The search strategy was restricted to English language publications using the combined terms: (strontium) and (implant or graft or biomaterial or bone substitute). Systematic reviews, reviews, and case reports were immediately excluded.

\section{Hand-searching \\ Unpublished data and hand-searching}

Unpublished data were sought by searching a database listing unpublished studies (OpenGray-www.opengrey. eu). A manual search was additionally conducted based on the reference lists of the selected papers. Further, electronic databases of the following journals, which were considered important to this review, were separately manually searched: Clinical Oral Implants Research, Bone, International Journal of Implant Dentistry, Osteoporosis International, Journal of Periodontology, Journal of Clinical Periodontology, Journal of Dentistry, Dentomaxillofacial Radiology, and Oral Surgery, Oral Medicine, Oral Pathology and Oral Radiology. Further, the bibliographic references of the included studies were also sought for possible relevant studies.

Titles, abstracts, and full texts of the search results were independently screened in duplicate by three reviewers (CRS, CBS, and RSN). When there was a disagreement, the reviewers discussed the study and reached consensus.

\section{Study selection and data extraction}

Three independent researchers (CRS, CBS, and RSN) conducted data extraction and validity assessment of the studies that met the inclusion criteria. Data was extracted focusing on the animal model, study groups, treatment start, duration of the treatment, period of examination, implant specification, evaluation methods, and results (outcomes), according to what was reported in each study 
(i.e., histomorphometry, biomechanical, microtomography, and serum analysis).

\section{Study outcomes}

Any qualitative and/or quantitative bone-related parameters which could explain the effects of the systemic administration of non-radioactive $\mathrm{Sr}$ on bone tissue of the animals, determining if and how this substance interacts with the bone tissue and bone-tissue regeneration, were included as relevant outcomes.

\section{Quality assessment and risk of bias of included studies}

Quality assessment of the studies was made according to SYRCLE's risk of bias tool for animal studies [28]. All ten domains (sequence generation, baseline characteristics, allocation concealment, random housing, performance blinding, random outcome assessment, detection blinding, incomplete outcome data, selective outcome reporting, and other sources of bias) of SYRCLE's tool were individually evaluated in terms of the risk of bias (no summary scores for the studies were included). Three reviewers (CRS, CBS, and RSN) independently assessed the studies for their quality. When there was a disagreement regarding the assessed data, a consensus meeting was carried out.

\section{Review}

\section{Search results}

The initial search for publications yielded 578 titles in MEDLINE (PubMed) database, and 152 in Scopus database. After duplicates were removed, there were a total of 553 titles to be screened. After initial screening, using the abstracts and key words, 37 publications remained (31 from PubMed and 6 from Scopus), that potentially met the inclusion criteria. Hand-searching did not reveal any additional publications. After full-text reading, publications which did not fulfill the inclusion criteria were excluded. From the selected full-texts, the main reason for exclusion was the methodology based on the local delivery of Sr, instead of its systemic use.

Finally, five studies reporting on the impact of systemic administration of $\mathrm{Sr}$ on the osseointegration of titanium implants were identified as eligible to be included in this systematic review. No additional publications were found from the bibliographic references of the included studies. No information on the use of systemic administration of strontium to enhance the remodeling of bone or bone substitute materials following grafting procedures were found. The study selection procedure is presented in the PRISMA flowchart (Fig. 1).

\section{Study outcomes}

Tables 1 and 2 show the information retrieved from the included studies. The studies differed notably with respect to the study population, Sr dose, time-point of medication start, duration of the treatment and period of evaluation, implant specification, and the methods.

In one of the studies included in the present review, including healthy female rats, SRAN at a dose of $625 \mathrm{mg} / \mathrm{kg} /$ day induced 33.9\% higher pull-out strength values, improved trabecular bone microarchitecture (bone volume/total volume, trabecular thickness, structure model index, and connectivity), bone biomechanical characteristics, and bone-to-implant contact, compared with a control (C) group [29].

In another study, including healthy male rats, SRAN at a dose of $800 \mathrm{mg} / \mathrm{kg} /$ day did not lead to higher implant pullout values, but showed increased bone volume fraction, trabecular number, and decreased trabecular separation compared with the control group, based on microtomographic and histomorphometric findings. Further, SRAN was not able to significantly enhance implant pull-out values when compared to the treatment with bisphosphonates (alendronate) of 4 and 8 weeks [30].

In three studies from the same research group, female rats with ovariectomy-induced (OVX) osteoporosis were included [31-33]. Although the same research group performed the studies, the results were based on diverse animal populations, as it can be inferred from the studies. Rats receiving a high dose of SRAN (SRAN ${ }_{\mathrm{H}}, 1000 \mathrm{mg} / \mathrm{kg} /$ day) showed an increased ratio between bone and total voxels in direct contact to the implant (1.9-fold) compared with a non-supplemented OVX group. Similar trends were observed regarding trabecular thickness (by 1.2-fold), bone volume/tissue volume (by 1.1-fold), trabecular number (by $90 \%$ ), and connectivity density (by $85.1 \%$ ), evaluated by microtomography. In fact, the $\mathrm{OVX}+\mathrm{SRAN}_{\mathrm{H}}$ group showed similar or even statistically significantly better values regarding the above-mentioned parameters when compared with a non-osteoporotic group, while the improvements induced with a smaller dose of SRAN $\left(\mathrm{SRAN}_{\mathrm{L}}\right.$, $500 \mathrm{mg} / \mathrm{kg} /$ day) did not reach statistical significance [32] compared with the control group. However, $\mathrm{SRAN}_{\mathrm{L}}$ animals showed improved implant osseointegration (as assessed by microtomography and histomorphometric evaluation) compared to a non-supplemented OVX group [33], but did not enhance bone-quality-related parameters when compared with a group receiving bisphosphonates (zolendronated and alendronate) [31]. Animals receiving bisphosphonates, however, showed significantly increased bone mineral density, and bone-to-implant contact and implant push-out values, when compared with a nonsupplemented OVX group [31].

\section{Quality assessment and risk of bias}

According to SYRCLE's risk of bias tool for animal studies [28], the studies were classified in relation to the risk of bias regarding their selection, performance, detection, 


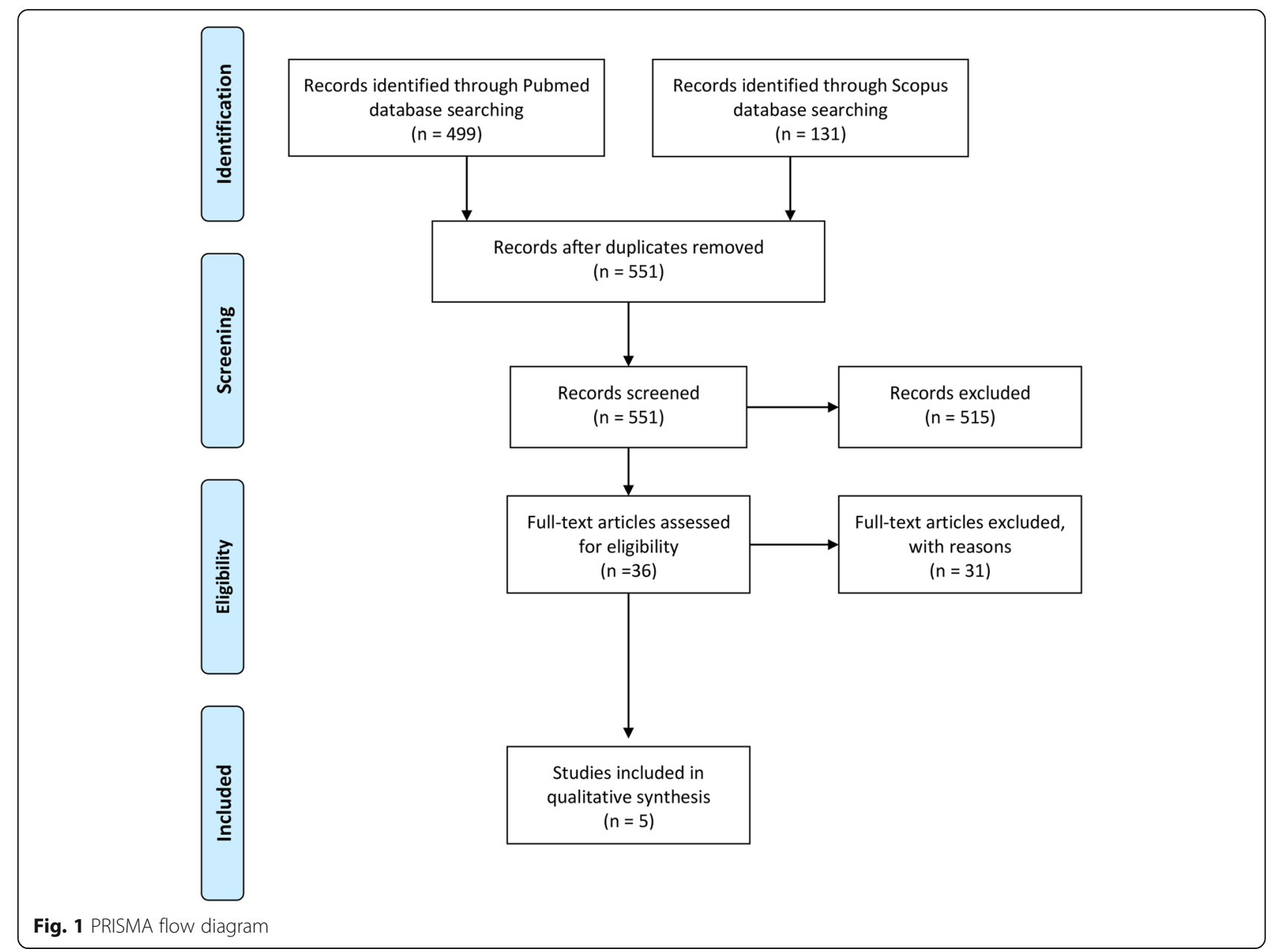

attrition, and reporting characteristics. All studies successfully met the criterion of not reporting their outcomes in a selective manner, and all proposed aims and elaborated hypotheses were adequately addressed in the results and discussion sessions of the papers. On the other hand, most studies were unclear regarding relevant steps, e.g., the housing of the animals, allocation concealment of the animals, whether outcome assessment was blinded, and whether incomplete outcome data existed and were not reported. Another possible source of bias may be the lack of consistent reporting regarding selection and justification of the posology of Sr supplementation. All these parameters represent relevant biases regarding the findings of the selected studies. The overall scoring for the included studies is presented in Table 3.

\section{Discussion}

Mechanism of action

$\mathrm{Sr}$ is a metabolic trace element closely related to calcium. $\mathrm{Sr}^{2+}$ ions are incorporated into bone by two main mechanisms: (a) a rapid uptake mechanism, dependent on osteoblast activity, whereby $\mathrm{Sr}^{2+}$ becomes absorbed via ion exchange processes with $\mathrm{Ca}^{2+}$ or binding to osteoid proteins, and (b) $\mathrm{Sr}^{2+}$ ions incorporate into the crystal lattice of the bone mineral phase. [34] When $\mathrm{Sr}^{2+}$ is present in higher levels than those required for normal cell physiology, it induces pharmacological effects on bone, through the activation of diverse cellular pathways [34].

Systemic use of non-radioactive $\mathrm{Sr}$ has showed promising results regarding the treatment of bone pathologies, such as osteoporosis and osteoarthritis [35-37], as it directly and positively interferes with bone mass, quality, and strength [38]. Further, in vitro studies have shown that $\mathrm{Sr}$ has the ability to increase bone formation $[39,40]$ while inhibiting osteoclast differentiation [41]. This dual action on bone remodeling, distinguishes $\mathrm{Sr}$ from the other traditional anti-osteoporotic agents, which either increase bone formation (intermittent parathyroid hormones) or inhibit bone resorption (bisphosphonates) [42]. Several mechanisms have been discussed for how 


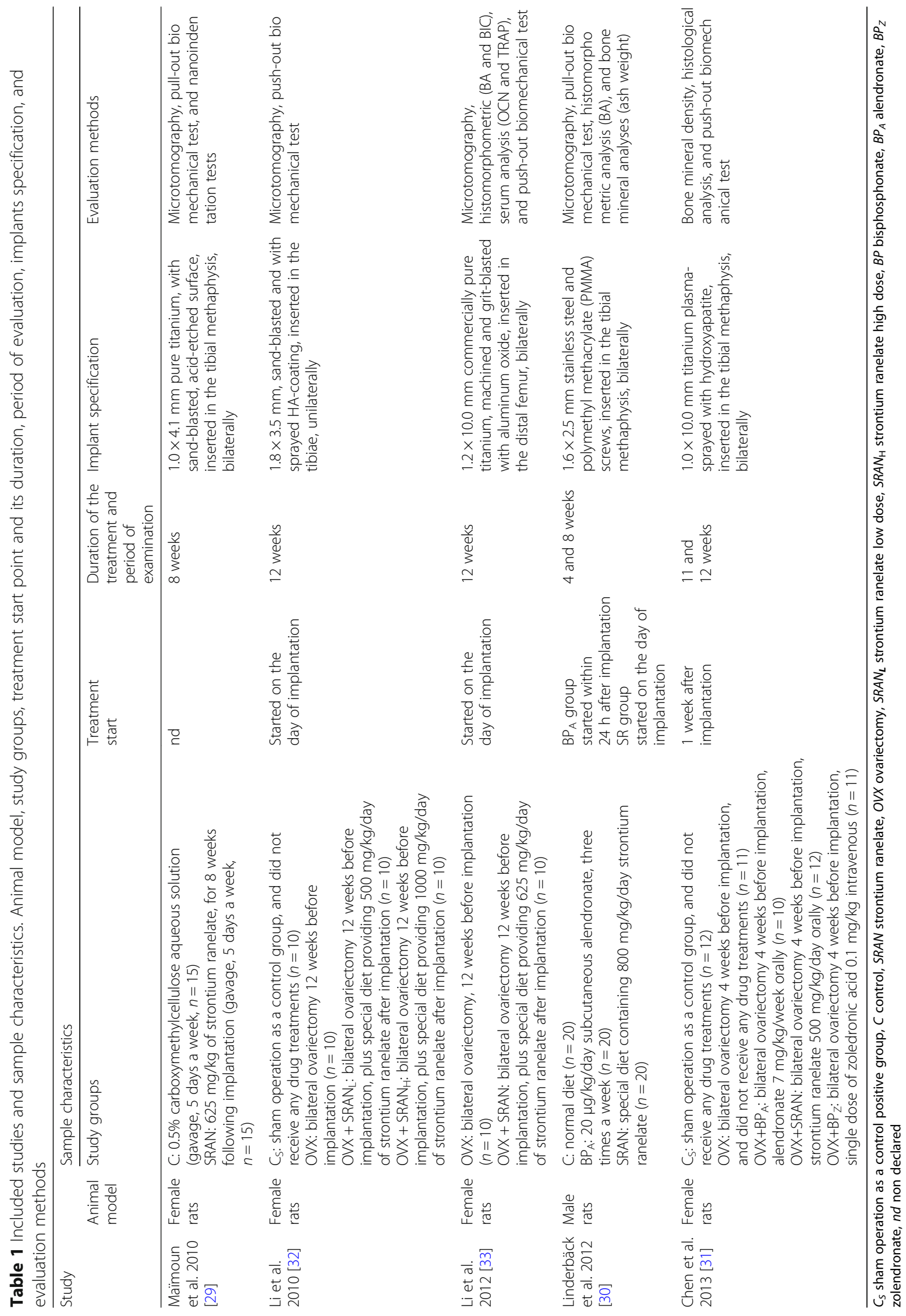


Table 2 Included studies and the evaluation methods employed, together with major outcomes for each method

\begin{tabular}{|c|c|c|c|c|c|c|}
\hline \multirow[t]{2}{*}{ Study } & \multirow[b]{2}{*}{$\begin{array}{l}\text { Bone mineral } \\
\text { density }\end{array}$} & \multicolumn{5}{|c|}{ Tests and overall results } \\
\hline & & Histomorphometric & Biomechanical & MicroCT & Nanoindentation & $\begin{array}{l}\text { Serum } \\
\text { analysis }\end{array}$ \\
\hline Maïmoun et al. 2010 [29] & - & - & SRAN $>C$ & $\begin{array}{l}\text { SRAN }>C \\
\text { (trabecular bone } \\
\text { microarchitecture } \\
\text { and BIC) }\end{array}$ & $\begin{array}{l}\text { SRAN }>C \\
\text { (elastic modulus, } \\
\text { tissue hardness, } \\
\text { and working energy) }\end{array}$ & - \\
\hline $\begin{array}{l}\text { Li et al. } 2010 \\
\text { [32] }\end{array}$ & - & - & $\begin{array}{l}\mathrm{OVX}+\mathrm{SR}_{H}=\mathrm{C}_{S}> \\
\mathrm{OVX}+\mathrm{SRAN}_{\mathrm{L}}>\mathrm{OVX}\end{array}$ & $\begin{array}{l}\text { OVX }+ \text { SRAN }_{H}>C_{S}> \\
\text { OVX }+ \text { SRAN }_{L}>\text { OVX }\end{array}$ & - & - \\
\hline $\begin{array}{l}\text { Li et al. } 2012 \\
\text { [33] }\end{array}$ & - & $\begin{array}{l}\text { OVX }+ \text { SRAN > OVX } \\
(B I C \text { and } B A)\end{array}$ & OVX + SRAN > OVX & OVX + SRAN > OVX & - & $\begin{array}{l}\text { OVX }+ \text { SRAN }> \\
\text { OVX } \\
\text { (OCN) } \\
\text { OVX }+ \text { SRAN }< \\
\text { OVX } \\
\text { (TRAP) }\end{array}$ \\
\hline $\begin{array}{l}\text { Linderbäck et al. } 2012 \\
\text { [30] }\end{array}$ & $\begin{array}{l}\mathrm{BP}_{\mathrm{A}}>\mathrm{SRAN}=\mathrm{C} \\
(4 \text { and } 8 \text { weeks })\end{array}$ & $\begin{array}{l}\mathrm{BP}_{\mathrm{A}}>\mathrm{SRAN}=\mathrm{C} \\
(4 \text { and } 8 \text { weeks })\end{array}$ & $\begin{array}{l}\mathrm{BP}_{\mathrm{A}}>\mathrm{SRAN}=\mathrm{C} \\
(4 \text { and } 8 \text { weeks })\end{array}$ & $\begin{array}{l}\mathrm{BP}_{\mathrm{A}}>\mathrm{SRAN}=\mathrm{C} \\
\text { (around implant) } \\
\mathrm{BP}_{\mathrm{A}}>\mathrm{SRAN}>\mathrm{C} \\
\text { (growth plate) }\end{array}$ & - & - \\
\hline $\begin{array}{l}\text { Chen et al. } \\
2013 \text { [31] }\end{array}$ & $\begin{array}{l}\mathrm{BP}_{\mathrm{Z}}=\mathrm{C}_{\mathrm{S}}>\mathrm{BP}_{\mathrm{A}} \\
=\mathrm{SRAN}>\mathrm{OVX}\end{array}$ & $\begin{array}{l}\mathrm{BP}_{\mathrm{Z}}=\mathrm{C}_{\mathrm{S}}>\mathrm{BP}_{\mathrm{A}}= \\
\mathrm{SRAN}>\mathrm{OVX}\end{array}$ & $\begin{array}{l}\mathrm{BP}_{\mathrm{Z}}=\mathrm{C}_{\mathrm{S}}>\mathrm{BP}_{\mathrm{A}}= \\
\text { SRAN }>\text { OVX }\end{array}$ & - & - & - \\
\hline
\end{tabular}

$C_{S}$ sham operation as a control positive group, $C$ control, $S R A N$ strontium ranelate, $O V X$ ovariectomy, $S R A N_{\mathrm{L}}$ strontium ranelate low dose, $S R_{H}$ strontium ranelate high dose, $B P$ bisphosphonate, $B P_{A}$ alendronate, $B P_{Z}$ zolendronate, $B I C$ bone contact implant, $B A$ bone area, $O C N$ osteocalcin, $T R A P$ tartrate-resistant acid phosphatase

systemic Sr-based therapy enhances bone formation [43-46]. Sr might activate the calcium-sensing (or another functionally different cation-sensing) receptor on osteoblasts, thereby leading to enhanced bone matrix production [46]. Another plausible mechanism is that $\mathrm{Sr}$ induces prostaglandin production and cyclooxygenase expression, thereby increasing osteoblastic differentiation [44]. Further, Sr might interact with fibroblast growth factor receptors, thereby increasing osteoblast synthetic activity [43]. At last, Sr also interacts with the mitogen-activated protein kinase (MAPK) signaling pathway, enhancing the differentiation of mesenchymal stem cells in osteogenic cells [45]. In regard with interfering with bone resorption, $\mathrm{Sr}$ enhances osteoprotegerin (OPG) expression in osteoblasts $[40,47,48]$ thereby reducing osteoclastogenesis [42].

Table 3 Assessment of risk of bias using SYRCLE's tool

\begin{tabular}{|c|c|c|c|c|c|}
\hline \multirow[t]{2}{*}{ Risk of bias } & \multicolumn{5}{|l|}{ Study } \\
\hline & Maïmoun et al. 2010 [29] & Li et al. 2010 [32] & Li et al. 2012 [33] & Linderbäck et al. 2012 [30] & Chen et al. 2013 [31] \\
\hline \multicolumn{6}{|l|}{ Selection } \\
\hline Sequence generation & L & $\mathrm{L}$ & $U$ & $L$ & L \\
\hline Baseline characteristics & L & $L$ & $\mathrm{~L}$ & $L$ & L \\
\hline Allocation concealment & $U$ & $\mathrm{~L}$ & $U$ & U & $U$ \\
\hline \multicolumn{6}{|l|}{ Performance } \\
\hline Random housing & $U$ & $U$ & $U$ & $U$ & $U$ \\
\hline Blinding & $U$ & $L$ & $U$ & $L$ & $U$ \\
\hline \multicolumn{6}{|l|}{ Detection } \\
\hline Random outcome assessment & $U$ & $U$ & $U$ & U & $U$ \\
\hline Blinding & $U$ & $U$ & $L$ & U & $U$ \\
\hline \multicolumn{6}{|l|}{ Attrition } \\
\hline Incomplete outcome data & $U$ & $U$ & $U$ & U & $U$ \\
\hline \multicolumn{6}{|l|}{ Reporting } \\
\hline Selective outcome reporting & L & $\mathrm{L}$ & $L$ & $L$ & L \\
\hline Other sources of bias & $\mathrm{H}$ & $\mathrm{H}$ & $\mathrm{H}$ & $\mathrm{H}$ & $\mathrm{H}$ \\
\hline
\end{tabular}

$L$ low risk of bias, $H$ high risk of bias, $U$ unclear 
Based on this dual effect, studies have suggested the use of $\mathrm{Sr}$ as an adjunct therapy in situations where enhanced bone tissue formation is needed [24, 46, 49]. One could hypothesize that any event dependent on bone formation, such as the osseointegration of implants, could benefit of strontium supplementation, i.e., osseointegration is enhanced due to improved bone formation rate and bone quality surrounding the implants $[1,2]$.

\section{Sr and implant osseointegration}

All studies included in this review tested the hypothesis that non-radioactive $\mathrm{Sr}$ supplementation would enhance implant osseointegration. Overall, the results of the included studies suggest that the systemic $\mathrm{Sr}$ administration enhances peri-implant bone quality and implant osseointegration, however to a moderate extent. Positive results regarding implant osseointegration and the quality of peri-implant bone tissue, as evaluated by various methods (microtomography, histomorphometry, biomechanical, nanoindentation, and serum analysis) were observed in studies with both osteoporotic and healthy animals [29, 30, 32, 33]. However, the effect of $\mathrm{Sr}$ was not as pronounced as that achieved with systemic administration of bisphosphonates [30, 31]. As mentioned, systemic administration of bisphosphonates is known to lead to denser peri-implant bone, larger amounts of bone-to-implant contact, and overall enhancement of osseointegration-related parameters [11, 12, 50]. However, the reports on bisphosphonate-related osteonecrosis affecting the jaws [13] have practically removed these drugs from the group of possible alternatives for enhancing osseointegration [51].

In the present review, $\mathrm{Sr}$ was always used in the form of SRAN. In contrast to what is reported for bisphosphonates, no reports of major side-effects due to the SRAN treatment were found in the literature. However, it is relevant to mention that the literature is limited regarding the risks and pitfalls associated to systemic SRAN therapy. In fact, one population study conducted in France showed that osteoporotic patients with a history of venous thromboembolism presented cardiovascular side effects related to SR (104 cases in 39 months) [52]. In the same study, another important side effect, cutaneous toxicity, was mentioned connected to the first few weeks of drug administration. In this context, $\mathrm{Sr}$ dosage may be an important issue. SRAN dose in the studies included in the present review varied immensely (from 500 to $1000 \mathrm{mg} / \mathrm{kg} /$ day). It is a known fact that the anabolic effects of SR on bone remodeling are dosedependent [23, 24], and indeed the positive effects of SR herein were observed with the higher doses [32, 33]. Clinical studies show efficacy regarding reduction of fracture risk in postmenopausal women with osteoporosis with a SRAN dose of $2 \mathrm{~g} /$ day [53]. Thus, a corresponding effective dose in a human adult with $60 \mathrm{~kg}$ of body weight would be 30-60 g/day. Despite the fact that high serum levels of strontium are required in rats in order to generate significant anabolic bone response [54], one could consider that if a dose 15 and 30 times higher than the clinical dose would be needed to have an effect on osseointegration, this could lead to toxicity in humans [55-57]. Clearly, this issue deserves further investigation.

The variability in the results of the studies included in this review, may not only relate to SRAN dose, but may somehow relate to differences in the time-period after ovariectomy, before the animals were included in the study, which differed greatly among studies (from 4 to 12 weeks). Although it is already defined in the literature that initial osteoporosis features appear already at 4 weeks after ovariectomy [58], in not a single study included in this review, were the osteoporotic conditions after ovariectomy confirmed by a specific test [31-33]. Thus, comparison of animals 4 and 12 weeks after ovariectomy in terms of bone architecture characteristics may not be considered optimal, since they represent diverse stages of osteoporotic state [58]. In the same context, in some studies, SRAN treatment started the same day of implant installation [30-33], while in other studies, treatment started 7 days after implantation [31]; SRAN treatment duration also varied much from among studies (from 4 to 12 weeks). Considering the fact that implant osseointegration in rats is completed within maximum 8 weeks after installation [59] and the fact that it is not yet known for how long should SRAN be used before it exerts a measureable effect on bone architecture, differences in the time-point of SRAN treatment start and its duration may have contributed to the variability in the results. Finally, differences in the evaluation methods used in the various studies, ranging from the gold-standard for osseointegration assessment, i.e., histomorphometry, to diverse biomechanical tests, and microtomography that has the inherent drawback of metal artifacts hampering osseointegration evaluation [60], may have also contributed to the observed variability in the results.

\section{Quality assessment and risk of bias}

According to SYRCLE's tool for assessing risk of bias [28], most studies were unclear regarding relevant steps in the selection, performance, detection, and attrition characteristics. On the other hand, there was a low risk for bias related to outcome reporting, so that the conclusions were often and straight-forward related towards the listed aims. Finally, a high risk for other biases, mostly related to inconsistency when defining and reporting the SRAN posology was seen in all included 
studies, something highly relevant, since it could directly reflect on the results and interfere in the reproducibility of the studies.

\section{Conclusions}

Based on the few studies included in this systematic review, it is possible to state that the systemic administration of $\mathrm{Sr}$, in the form of SRAN, seems to enhance periimplant bone quality and implant osseointegration, however, to a moderate extent. Further studies should focus on standardization of the study designs to properly assess the effects of Sr, including parameters such SRAN dose, administration start point, and duration of administration, further allowing the assessment of potential risks/benefits of SRAN use.

\section{Abbreviations}

Medline: Medical Literature Analysis and Retrieval System Online:

OVX: Ovariectomy; Sr: Strontium; SRAN: Strontium ranelate;

SYRCLE: Systematic Review Centre for Laboratory animal Experimentation

\section{Funding}

This study was financed by the Brazilian agencies CAPES (003628/2015-09) and CNPq (scholarship).

\section{Availability of data and materials}

This article is distributed under the terms of the Creative Commons Attribution 4.0 International License (http://creativecommons.org/licenses/by/4.0/), which permits unrestricted use, distribution, and reproduction in any medium, provided you give appropriate credit to the original author(s) and the source, provide a link to the Creative Commons license, and indicate if changes were made.

\section{Authors' contributions}

CRS, CBS, and RSN performed the search, conducted the review, and drafted the manuscript. RACM and EM-Jr assisted in assessing the studies, carried out the editing of the manuscript, and helped in the manuscript drafting. AS assisted in designing the systematic review, discussing the findings, and drafting the manuscript. All authors read and approved the final manuscript.

\section{Ethics approval and consent to participate}

This review was executed in accordance with PRISMA (Preferred Reporting Items for Systematic Reviews and Meta-Analyses), and the Cochrane Handbook for Systematic Reviews of Interventions, and no approval by an ethics committee is demanded.

\section{Consent for publication}

All participants consented to publish their information details.

\section{Competing interests}

Cássio Rocha Scardueli, Carolina Bizelli-Silveira, Rosemary Adriana C. Marcantonio, Elcio Marcantonio Jr, Andreas Stavropoulos, and Rubens Spin-Neto declare that they have no competing interests.

\section{Publisher's Note}

Springer Nature remains neutral with regard to jurisdictional claims in published maps and institutional affiliations.

\section{Author details}

'Department of Dentistry and Oral Health, Aarhus University, Aarhus, Denmark. ²Department of Periodontology, São Paulo State University (Unesp), School of Dentistry, Araraquara, São Paulo, Brazil. ${ }^{3}$ Department of Periodontology, Faculty of Odontology, University of Malmö, Malmö, Sweden.
Received: 14 November 2017 Accepted: 23 April 2018

Published online: 17 July 2018

\section{References}

1. Davies JE. Mechanisms of endosseous integration. Int J Prosthodont. 1998 11:391-401.

2. Davies JE. Understanding peri-implant endosseous healing. J Dent Educ 2003:67:932-49

3. Sakka S, Baroudi K, Nassani MZ. Factors associated with early and late failure of dental implants. J Investig Clin Dent. 2012;3:258-61.

4. Bastos AS, Spin-Neto R, Conte-Neto N, Galina K, Boeck-Neto RJ, Marcantonio $C$, et al. Calvarial autogenous bone graft for maxillary ridge and sinus reconstruction for rehabilitation with dental implants. J Oral Implantol. 2014:40:469-78

5. Dimitriou R, Jones E, McGonagle D, Giannoudis PV. Bone regeneration: current concepts and future directions. BMC Med. 2011;9:66.

6. Apostu D, Lucaciu O, Lucaciu GD, Crisan B, Crisan L, Baciut M, et al. Systemic drugs that influence titanium implant osseointegration. Drug Metab Rev. 2017;49:92-104

7. Qi MC, Zhou XQ, Hu J, Du ZJ, Yang JH, Liu M, et al. Oestrogen replacement therapy promotes bone healing around dental implants in osteoporotic rats. Int J Oral Maxillofac Surg. 2004:33:279-85.

8. Gabet $Y$, Muller R, Levy J, Dimarchi R, Chorev M, Bab I, et al. Parathyroid hormone 1-34 enhances titanium implant anchorage in low-density trabecular bone: a correlative micro-computed tomographic and biomechanical analysis. Bone. 2006:39:276-82.

9. Li Y, Gao Y, Song G, Liu X, Hu J. Additive effects of estrogen replacement therapy and bisphosphonates on osseointegration of hydroxyapatite-coated titanium screws in ovariectomized rats. Oral Surg Oral Med Oral Pathol Oral Radiol Endod. 2010;109:700-5.

10. Viera-Negron YE, Ruan WH, Winger JN, Hou X, Sharawy MM, Borke JL. Effect of ovariectomy and alendronate on implant osseointegration in rat maxillary bone. J Oral Implantol. 2008;34:76-82.

11. Rogers MJ, Gordon S, Benford HL, Coxon FP, Luckman SP, Monkkonen J, et al. Cellular and molecular mechanisms of action of bisphosphonates. Cancer. 2000;88:2961-78.

12. Vohra F, Al-Rifaiy MQ, Almas K, Javed F. Efficacy of systemic bisphosphonate delivery on osseointegration of implants under osteoporotic conditions: lessons from animal studies. Arch Oral Biol. 2014;59:912-20.

13. Polymeri AA, Kodovazenitis GJ, Polymeris AD, Komboli M. Bisphosphonates: clinical applications and adverse events in dentistry. Oral Health Prev Dent. 2015:13:289-99.

14. Pemmer B, Hofstaetter JG, Meirer F, Smolek S, Wobrauschek P, Simon R, et al. Increased strontium uptake in trabecular bone of ovariectomized calcium-deficient rats treated with strontium ranelate or strontium chloride. J Synchrotron Radiat. 2011:18:835-41.

15. Peng S, Liu XS, Zhou G, Li Z, Luk KD, Guo XE, et al. Osteoprotegerin deficiency attenuates strontium-mediated inhibition of osteoclastogenesis and bone resorption. J Bone Miner Res. 2011;26:1272-82.

16. Seeman E, Vellas B, Benhamou C, Aquino JP, Semler J, Kaufman JM, et al. Strontium ranelate reduces the risk of vertebral and nonvertebral fractures in women eighty years of age and older. J Bone Miner Res. 2006;21:1113-20.

17. Tournis S. Improvement in bone strength parameters. The role of strontium ranelate. J Musculoskelet Neuronal Interact. 2007;7:266-7.

18. Tournis S, Economopoulos D, Lyritis GP. Strontium ranelate: a nove treatment in postmenopausal osteoporosis. Ann N Y Acad Sci. 2006;1092:403-7.

19. Likins RC, Posner AS, Kunde ML, Craven DL. Comparative metabolism of calcium and strontium in the rat. Arch Biochem Biophys. 1959:83:472-81.

20. Burlet N, Reginster JY. Strontium ranelate: the first dual acting treatment for postmenopausal osteoporosis. Clin Orthop Relat Res. 2006:443:55-60.

21. Reginster JY, Sarlet N, Lejeune E, Leonori L. Strontium ranelate: a new treatment for postmenopausal osteoporosis with a dual mode of action. Curr Osteoporos Rep. 2005;3:30-4.

22. Marie PJ, Hott M, Modrowski D, De Pollak C, Guillemain J, Deloffre P, et al. An uncoupling agent containing strontium prevents bone loss by depressing bone resorption and maintaining bone formation in estrogendeficient rats. J Bone Miner Res. 1993:8:607-15.

23. Ammann P, Shen V, Robin B, Mauras Y, Bonjour JP, Rizzoli R. Strontium ranelate improves bone resistance by increasing bone mass and improving architecture in intact female rats. J Bone Miner Res. 2004;19:2012-20. 
24. Buehler J, Chappuis P, Saffar $J$, Tsouderos $Y$, Vignery A. Strontium ranelate inhibits bone resorption while maintaining bone formation in alveolar bone in monkeys (Macaca fascicularis). Bone. 2001;29:176-9.

25. Arlot ME, Jiang Y, Genant HK, Zhao J, Burt-Pichat B, Roux JP, et al. Histomorphometric and microCT analysis of bone biopsies from postmenopausal osteoporotic women treated with strontium ranelate. J Bone Miner Res. 2008;23:215-22.

26. Moher D, Liberati A, Tetzlaff J, Altman DG, Group P. Preferred reporting items for systematic reviews and meta-analyses: the PRISMA statement. BMJ. 2009;339:b2535

27. JP H, S G. Cochrane Handbook for Systematic Reviews of Interventions, version 5.1.0.: The Cochrane Collaboration; 2011

28. Hooijmans CR, Rovers MM, de Vries RB, Leenaars M, Ritskes-Hoitinga M, Langendam MW. SYRCLE's risk of bias tool for animal studies. BMC Med Res Methodol. 2014:14:43.

29. Maimoun L, Brennan TC, Badoud I, Dubois-Ferriere V, Rizzoli R, Ammann P. Strontium ranelate improves implant osseointegration. Bone. 2010:46:1436-41.

30. Linderback P, Agholme F, Wermelin K, Narhi T, Tengvall P, Aspenberg P. Weak effect of strontium on early implant fixation in rat tibia. Bone. 2012;50: 350-6.

31. Chen B, Li Y, Yang X, Xu H, Xie D. Zoledronic acid enhances bone-implant osseointegration more than alendronate and strontium ranelate in ovariectomized rats. Osteoporos Int. 2013;24:2115-21.

32. Li Y, Feng G, Gao Y, Luo E, Liu X, Hu J. Strontium ranelate treatment enhances hydroxyapatite-coated titanium screws fixation in osteoporotic rats. J Orthop Res. 2010;28:578-82.

33. Li Y, Li X, Song G, Chen K, Yin G, Hu J. Effects of strontium ranelate on osseointegration of titanium implant in osteoporotic rats. Clin Oral Implants Res. 2012;23:1038-44.

34. Dahl SG, Allain P, Marie PJ, Mauras Y, Boivin G, Ammann P, et al. Incorporation and distribution of strontium in bone. Bone. 2001;28:446-53.

35. Deeks ED, Dhillon S. Spotlight on strontium ranelate: in postmenopausal osteoporosis. Drugs Aging. 2010;27:771-3

36. Kaufman JM, Audran M, Bianchi G, Braga V, Diaz-Curiel M, Francis RM, et al. Efficacy and safety of strontium ranelate in the treatment of osteoporosis in men. J Clin Endocrinol Metab. 2013:98:592-601.

37. Reginster JY, Felsenberg D, Boonen S, Diez-Perez A, Rizzoli R, Brandi ML, et al. Effects of long-term strontium ranelate treatment on the risk of nonvertebral and vertebral fractures in postmenopausal osteoporosis: results of a five-year, randomized, placebo-controlled trial. Arthritis Rheum. 2008;58. 1687-95.

38. Marie PJ, Felsenberg D, Brandi ML. How strontium ranelate, via opposite effects on bone resorption and formation, prevents osteoporosis. Osteoporos Int. 2011;22:1659-67.

39. Canalis E, Hott M, Deloffre P, Tsouderos $Y$, Marie PJ. The divalent strontium salt S12911 enhances bone cell replication and bone formation in vitro. Bone. 1996;18:517-23.

40. Peng S, Liu XS, Wang T, Li Z, Zhou G, Luk KD, et al. In vivo anabolic effect of strontium on trabecular bone was associated with increased osteoblastogenesis of bone marrow stromal cells. J Orthop Res. 2010;28: 1208-14.

41. Bonnelye $E$, Chabadel A, Saltel F, Jurdic P. Dual effect of strontium ranelate: stimulation of osteoblast differentiation and inhibition of osteoclast formation and resorption in vitro. Bone. 2008;42:129-38.

42. Peng $\mathrm{S}, \mathrm{Pan} \mathrm{H}$, Lu WW. Osteoprotegerin plays a key role in the dual action of strontium on bone remodeling: evidences from bench to clinic. Bone. 2012;50:1203-4.

43. Caverzasio J, Thouverey C. Activation of FGF receptors is a new mechanism by which strontium ranelate induces osteoblastic cell growth. Cell Physiol Biochem. 2011;27:243-50.

44. Choudhary S, Halbout P, Alander C, Raisz L, Pilbeam C. Strontium ranelate promotes osteoblastic differentiation and mineralization of murine bone marrow stromal cells: involvement of prostaglandins. J Bone Miner Res. 2007;22:1002-10

45. Peng S, Zhou G, Luk KD, Cheung KM, Li Z, Lam WM, et al. Strontium promotes osteogenic differentiation of mesenchymal stem cells through the Ras/MAPK signaling pathway. Cell Physiol Biochem. 2009;23:165-74.

46. Pors NS. The biological role of strontium. Bone. 2004;35:583-8.

47. Atkins GJ, Welldon KJ, Halbout P, Findlay DM. Strontium ranelate treatment of human primary osteoblasts promotes an osteocyte-like phenotype while eliciting an osteoprotegerin response. Osteoporos Int. 2009;20:653-64.
48. Brennan TC, Rybchyn MS, Green W, Atwa S, Conigrave AD, Mason RS. Osteoblasts play key roles in the mechanisms of action of strontium ranelate. Br J Pharmacol. 2009;157:1291-300.

49. Verberckmoes SC, De Broe ME, D'Haese PC. Dose-dependent effects of strontium on osteoblast function and mineralization. Kidney Int. 2003;64 534-43.

50. Berardi D, Carlesi T, Rossi F, Calderini M, Volpi R, Perfetti G. Potential applications of biphosphonates in dental surgical implants. Int J Immunopathol Pharmacol. 2007:20:455-65.

51. Javed F, Almas K. Osseointegration of dental implants in patients undergoing bisphosphonate treatment: a literature review. J Periodontol. 2010;81:479-84

52. Jonville-Bera A, Autret-Leca E. Ranélate de strontium (Protelos): effets indésirables rapportés en France. Presse Med. 2011:40:9.

53. O'Donnell S, Cranney A, Wells GA, Adachi JD, Reginster JY. Strontium ranelate for preventing and treating postmenopausal osteoporosis. Cochrane Database Syst Rev. 2006:4:CD005326.

54. Fuchs RK, Allen MR, Condon KW, Reinwald S, Miller LM, McClenathan D, et al. Strontium ranelate does not stimulate bone formation in ovariectomized rats. Osteoporos Int. 2008;19:1331-41.

55. Morohashi T, Sano T, Yamada S. Effects of strontium on calcium metabolism in rats. I. A distinction between the pharmacological and toxic doses. Jpn J Pharmacol. 1994;64:155-62.

56. Sobel AE, Cohen J, Kramer B. The nature of the injury to the calcifying mechanism in rickets due to strontium. Biochem J. 1935;29:2640-5.

57. Reinholt FP, Hjerpe A, Jansson K, Engfeldt B. Stereological studies on the epiphyseal growth plate in strontium-induced rickets. With special reference to the distribution of matrix vesicles. J Bone Joint Surg Am. 1984;66:1274-80.

58. Lelovas PP, Xanthos TT, Thoma SE, Lyritis GP, Dontas IA. The laboratory rat as an animal model for osteoporosis research. Comp Med. 2008;58:424-30.

59. Glosel B, Kuchler U, Watzek G, Gruber R. Review of dental implant rat research models simulating osteoporosis or diabetes. Int J Oral Maxillofac Implants. 2010;25:516-24.

60. Ejima K, Omasa S, Motoyoshi M, Arai Y, Kai Y, Amemiya T, et al. Influence of metal artifacts on in vivo micro-CT for orthodontic mini-implants. J Oral Sci. 2012;54:55-9.

\section{Submit your manuscript to a SpringerOpen ${ }^{\circ}$ journal and benefit from:}

- Convenient online submission

- Rigorous peer review

- Open access: articles freely available online

- High visibility within the field

Retaining the copyright to your article

Submit your next manuscript at springeropen.com 